\title{
Aortopulmonary Window Associated with a Patent Ductus Arteriosus in an Adult
}

\author{
Chouaib $\mathrm{H}^{*}$, Fellat N, Hatem S
}

Cardiology a Unit, Ibn Sina University Hospital, Rabat, Morocco

DOI: $10.36347 /$ simcr.2020.v08i03.043

| Received: 06.01.2020 | Accepted: 13.01.2020 | Published: 30.03.2020

*Corresponding author: Chouaib $\mathrm{H}$

Abstract

Case Report

Aortopulmonary window (APW) is an uncommon congenital cardiac malformation, accounting for $0.1 \%$ of all congenital cardiac diseases. It results from an incomplete division between the ascending aorta and the pulmonary artery. Clinical and hemodynamic presentation of this condition depends on the size of the defect and on the associated lesions. It is usually fatal in infancy or childhood if untreated with the development of irreversible pulmonary hypertension. Very few cases of those who have survived to adulthood have been described. Herein, we report the case of a 42-year-old female patient who presented with an Eisenmenger syndrome and pulmonary hypertension that she first declared at the age of 39-years-old, with special attention to clinical, echocardiographic and angiographic data, leading us to a diagnosis of APW associated with PDA.

Keywords: Aortopulmonary window, Patent ductuc arteriosus, Adult congenital heart disease, Pulmonary arterial hypertension.

Copyright @ 2020: This is an open-access article distributed under the terms of the Creative Commons Attribution license which permits unrestricted use, distribution, and reproduction in any medium for non-commercial use (NonCommercial, or CC-BY-NC) provided the original author and source are credited.

\section{INTRODUCTION}

The aortopulmonary window (APW) is a rare congenital cardiac malformation $(0.2 \%-0.6 \%$ of all congenital heart diseases)[1], where an abnormal communication exists between the ascending aorta and trunk and/or right pulmonary branch, in the presence of two separate sigmoid valve planes which differentiates it from truncus arteriosus (TA).

According to the location of the lesion, several classifications have been proposed. The classification most often used is that of Mori et al. [2], which divides them in:

- Type I or proximal, the most common (70\%): the communication is usually rounded and located above the semilunar valves, between the ascending aorta and the pulmonary trunk. Embryologically, it results from abnormal septation of the aortopulmonary trunk.

- Type II or distal (25\%): the defect, of spiral form, involves the pulmonary bifurcation at the level of the right pulmonary artery; it results from abnormal migration of the sixth aortic arch, often associated with other defects, particularly hypoplasia or even aortic arch interruption.

- And finally type III (5\%), characterized by total absence of the aortopulmonary septum resulting from the combination of proximal and distal defects; this is thought to be due to unequal partitioning of the aortopulmonary trunk [3].

Aortopulmonary window frequently occurs as an isolated lesion though it can be associated with other cardiac abnormalities in one third to one half of cases, which complicates the diagnosis and methods of surgical repair [4].

This condition originates an important leftright shunt. Its natural history is characterized by the early manifestations of congestive heart failure, severe pulmonary hypertension and Eisenmenger syndrome [5]. It is fatal in most cases if untreated surgically in the first months of life. The few patients, who do survive into adulthood, usually have a fixed pulmonary hypertension, contraindicating the closure of the defect [6]. Antenatal diagnosis is rare.

We describe the rare case of what we believe to be the oldest patient with an unrepaired distal APW associated with a patent ductus arteriosus reported to date, causing Eisenmenger syndrome, who remained asymptomatic until the age of 39-years-old, and discuss the clinical and investigative features of this condition. 


\section{Case Report}

A 42-year-old female patient, $68 \mathrm{Kg}$ of body weight, was admitted to our institution for the assessment of a grade IV dyspnea and fatigue. The patient was born to a first-degree consanguineous marriage, with no personal history of recurrent respiratory infections. She expressed that she had no respiratory or cardiovascular symptoms until three years before her admission, where she experienced a progressive onset of dyspnea, initially exertional and recently during rest, associated with a paroxysmal nocturnal dyspnea. The patient also described the occurrence of angina and lightheadedness during exertion.

Physical examination on admission revealed mild tachypnea at rest, blood pressure at $110 / 50 \mathrm{mmHg}$, saturation at $85 \%$ on room air, with chronic central cyanosis, nail clubbing and conjunctival hyperemia. A fixed split second heart sound was found on auscultation with no perceivable murmur. The patient also had a jugular venous distention, discrete peripheral edema and a positive Harzer's sign.

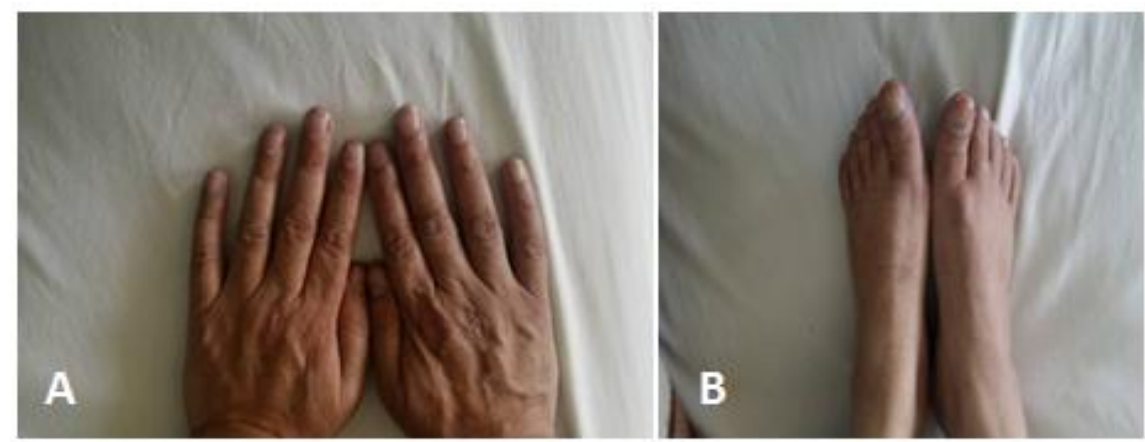

Fig-1, A \& B: Photos of our patient's extremities showing cyanosis and nail clubbing

In room air, she had hypoxemia $(\mathrm{PaO} 2$ : $52 \mathrm{mmHg}$ ) and normocarbia $(\mathrm{PaCO} 2: 39 \mathrm{mmHg})$ with oxygen saturation $(\mathrm{SaO} 2)$ of $87 \%$. Hemoglobin was 20 $\mathrm{g} / \mathrm{dL}$, and hematocrit was $62 \%$.
Chest X-ray demonstrated cardiomegaly (Cardiothoracic Index of 0,62), elevated cardiac apex, enlarged right atrium. It revealed dilatation of the main pulmonary artery with prominent pulmonary outflow tract, enlarged pulmonary arteries with mild pruning of peripheral pulmonary vessels.

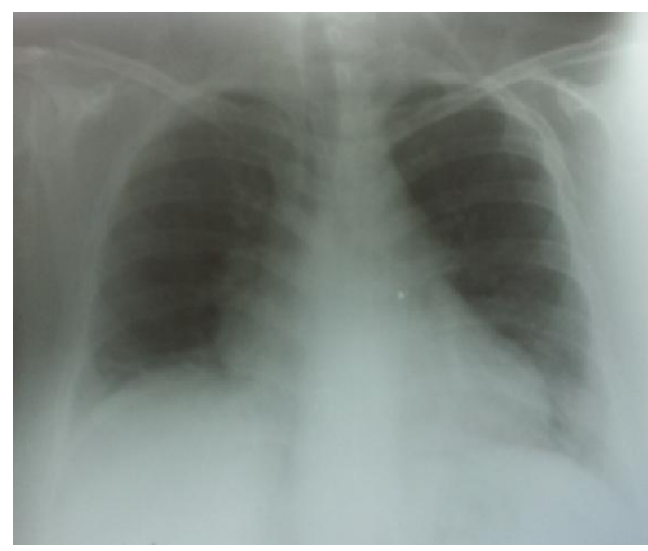

Fig-2: Chest X-Ray of our patient: Cardiomegaly and mild pulmonary congestion

Electrocardiography showed regular sinus rhythm at 90 beats/minute with right heart axis deviation, right ventricular hypertrophy, and negative anteroseptal and biphasic inferior $\mathrm{T}$ waves.

Transthoracic echocardiography showed biventricular hypertrophy predominantly right-sided, with no obstacles in the outflow tracts, a moderatly dilated right atrium, enlarged pulmonary trunk, trivial tricuspid and pulmonary regurgitations, thus, pulmonary artery pressure evaluation was difficult. A
$10 \mathrm{~mm}$ patent ductus arteriosus was identified with a left-to-right shunt. There was no abnormality in the coronary arteries, and the two separate aortic and pulmonary valve planes were present. The 2D parasternal short axis view showed a clear distal small defect between the ascending aorta and the pulmonary bifurcation at the level of the right pulmonary artery, and the presence of the $\mathrm{T}$ sign (cf. infra, discussion). Color Doppler demonstrated unidirectional flow and a diastolic reversal flow from the ascending aorta to the pulmonary artery. 

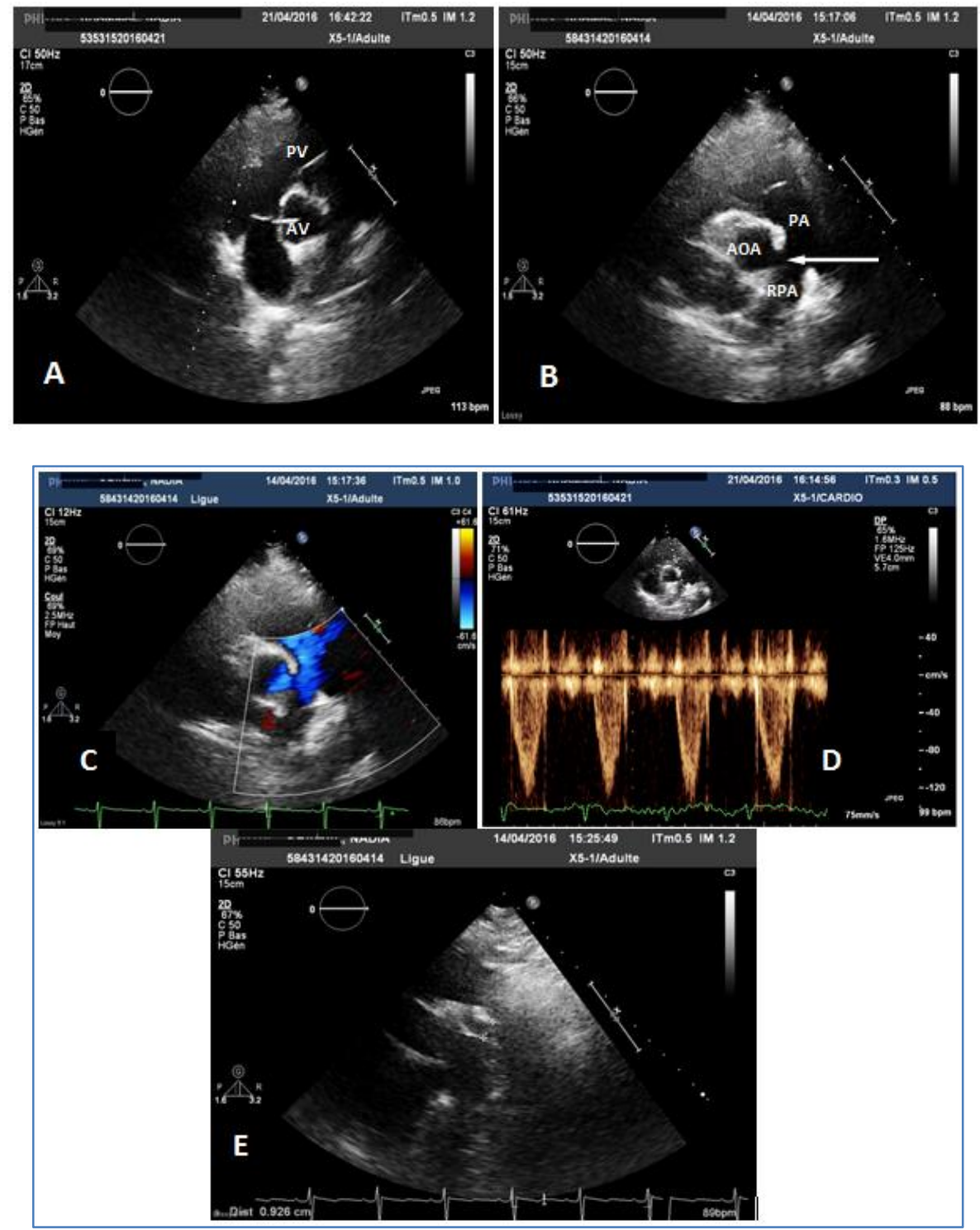

Fig-3: Echographic images of our patient

Parasternal short axis view: A. 2D image at the level of the valve planes shows the two separate aortic and pulmonary sigmoid valves. B. 2D image over the aortic valve plane shows a clear distal defect between the ascending aorta and the pulmonary bifurcation at the level of the right pulmonary artery, and the presence of the $\mathrm{T}$ sign. C. Unidirectional flow by color Doppler blue flow from the aorta to the pulmonary artery. D. Doppler diastolic reversal flow from the ascending aorta to the pulmonary artery. AV-aortic valve, PVpulmonary valve, AOA-ascending aorta, RPA-right pulmonary artery. Upper parasternal plane: E. 2D image shows PDA.

The patient underwent right and left heart catheterization that revealed a left-to-right shunt through the defect and severe isosystemic pulmonary hypertension (pulmonary artery pressure of: 131/73/101 $\mathrm{mmHg}$ ). Hemodynamic data are presented in Table 1.

Cardiac output calculation by Fick method resulted in a value of $3,02 \mathrm{l} / \mathrm{min}$. Vasoreactivity and oxygen tests were not performed.

Table-1: Hemodynamic data of our patient

\begin{tabular}{|c|c|c|c|c|c|c|c|}
\hline $\begin{array}{c}\text { Sats } \\
\text { RV }\end{array}$ & $\begin{array}{c}\text { Sats } \\
\text { MPA }\end{array}$ & $\begin{array}{c}\text { Sats } \\
\text { FA }\end{array}$ & $\begin{array}{c}\text { RV } \\
\text { pressure }\end{array}$ & $\begin{array}{c}\text { MPA } \\
\text { pressure }\end{array}$ & $\begin{array}{c}\text { LV } \\
\text { pressure }\end{array}$ & PVRI Pre & Qp/Qs \\
\hline \multicolumn{7}{|c|}{$\left(\begin{array}{c|c|c|}(\mathrm{mmHg}) \\
\text { (\%) }\end{array}\right.$} & \multicolumn{5}{|l}{$\begin{array}{l}\text { Woods } \\
\text { Units.m2) }\end{array}$} & \\
\hline 60 & 82 & 85 & $136 / 7$ & $\begin{array}{c}131 / 73 \\
(101)\end{array}$ & $111 / 21$ & - & 5,4 \\
\hline
\end{tabular}


Sats-oxygen saturation, RV-right ventricle, MPA-main pulmonary artery, FA-femoral artery, LVleft ventricule, P-pressure, Pre-pre-oxygen administration, PVRI-pulmonary vascular resistance index

\begin{tabular}{|c|c|c|c|c|c|c|c|c|}
\hline \multicolumn{2}{|c|}{ Résistance $(\mathrm{D} / \mathrm{S})$} & \multirow{2}{*}{$\frac{(0 / 01)}{564}$} & \multicolumn{2}{|c|}{ Teneur en 02 (ml/Différence $02(\mathrm{ml} /)$} & \multicolumn{4}{|c|}{ Déthit (1/min) } \\
\hline RVP & 398 & & AS 02:231,20 & SA.SV (AV) 68,00 & Qp: & 16,33 & Opi: & 9,78 \\
\hline RVPT & 495 & 826 & VS 02: 163,20 & VP.AR (VA) 13,60 & Qs: & 3,02 & Osi: & 1,81 \\
\hline RVS: & 2434 & 4064 & VP 02: 236,64 & PV-SV (M) 73,44 & Qe: & 3,02 & Qei: & 1.81 \\
\hline RVST: & 2751 & 4594 & AP 02: 223,04 & & Op/Os: & 5,40 & & \\
\hline RVPIRVS & 0,14 & & & & $G>0$ & 13,31 & $81 \%$ & \\
\hline RVPT/RVST: & 0,18 & & & & $D / G$ & & & \\
\hline
\end{tabular}

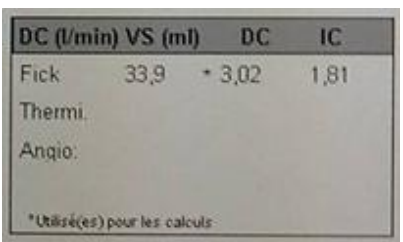

\section{Aortic root injection showed the distal APW}
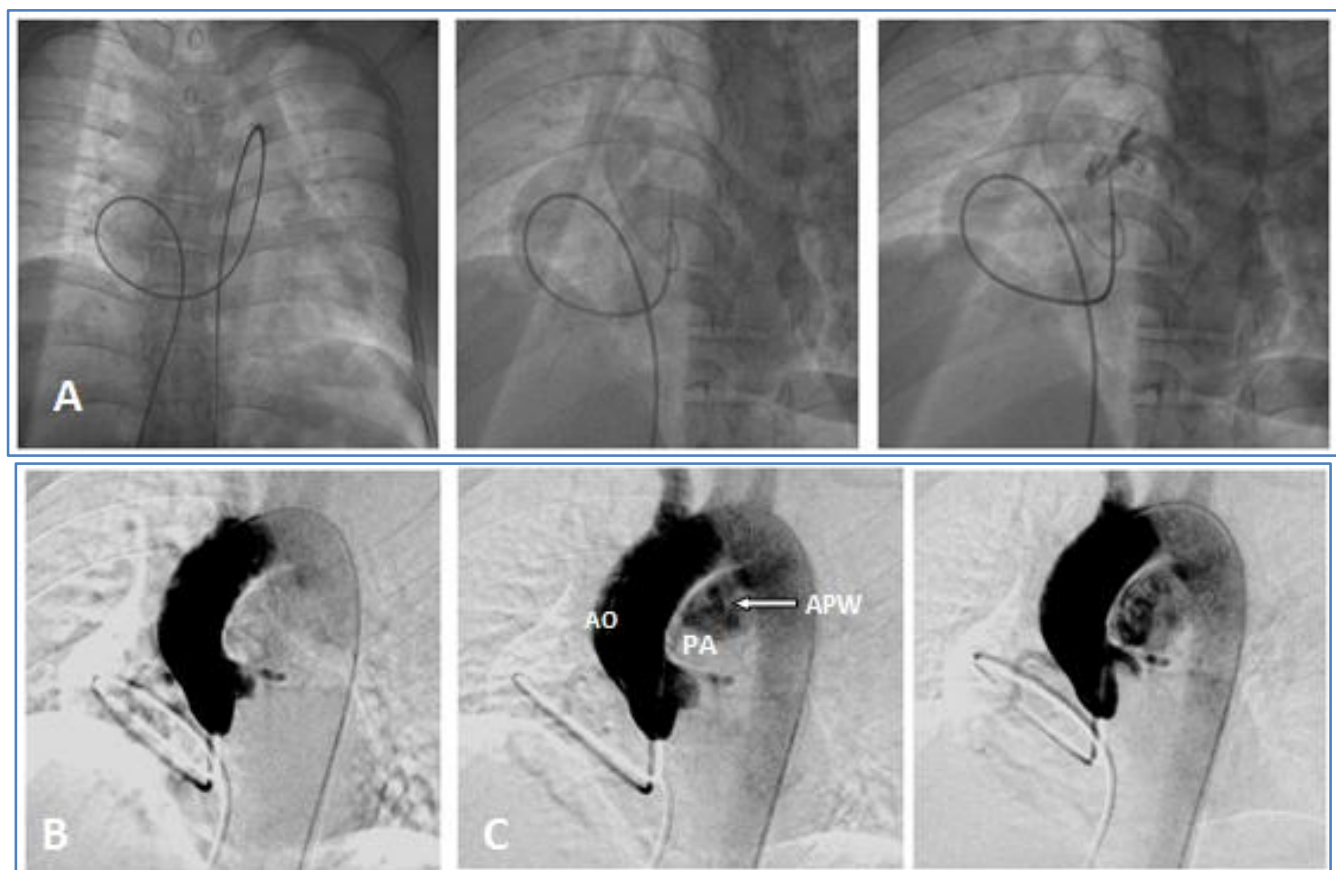

Fig-4: Hemodynamic PDA and APW study of our patient: A. Right catheterization. Through the PDA, the catheter was advanced from the pulmonary artery branch to the descending aorta. B. Stop flow aortography, lateral view. Presence of a distal APW. (The two vessels filled simultaneously in the presence of two separate sigmoid valves). C. Lateral aortogram showing APW (white arrow). AO-ascending aorta, PApulmonary artery, PDA-patent ductus arteriosus, APW-aortopulmonary window

Oxygen and high dose aspirin (300mg) were promptly started. On the second day of the treatment, $\mathrm{SaO} 2$ was $90 \%$ in room air. Because of the presence of Eisenmenger syndrome, closure of the APW was contraindicated. The patient lacked financial means to afford specific vasodilatators.

At follow-up, she was asymptomatic at rest; however she had dyspnea and became desaturated at minimal exertion.

\section{DISCUSSION}

The APW is a rare congenital cardiac malformation $(0.2 \%-0.6 \%$ of all congenital heart diseases)[1]. It results from an incomplete division of the distal truncoaortic sac into the aorta and pulmonary trunks [7].

According to the location of the lesion, several classifications have been proposed. The classification most often used is that of Mori et al. which divides them in type I or proximal, the most common $(70 \%)$, type II or distal (25\%) and type III or total (5\%)[2].

The most common associated lesions are: interrupted aortic arch (15-20\%), patent ductus arteriosus $(11 \%)$, coronary artery anomalies $(8 \%)$ and ventricular septal defect (8\%). Other associated malformations include right aortic arch, tetralogy of Fallot, subvalvular aortic stenosis, bicuspid aortic valve, ventriculoarterial discordance, double aortic arch and tricuspid atresia [8].

The size of the APW determines its hemodynamic effects and clinical course. There is a significant arterial level systemic to pulmonary shunt with large defects, causing heart failure and pulmonary hypertension and can lead rapidly to obstructive pulmonary vascular disease, resulting in death in infancy or late in the first or second decade. 
The clinical diagnosis of APW should always be suspected in any child with heart failure and signs of significant left-right shunt, such as dilatation of the left cavities, particularly in the presence of a nonspecific mitral regurgitation with a normal mitral valve morphology [9], recurrent respiratory infections and low weight gain. The continuous cardiac murmur characteristic of the disease is auscultated in fewer than half of the cases [10]. When there are associated malformations, the clinical manifestations can be atypical [8].

Adult diagnosis of APW is rarer, studies suggest that adult patients with APW present with symptoms of shortness of breath on exertion and often palpitations, and may also have a history of recurrent lower respiratory tract infections in childhood. A continuous cardiac murmur is audible approximately in half or more of the patients, and if the APW is large, there will be evidence of PAH[5,11].

Our patient had been asymptomatic until adulthood; she presented with a left to right shunting, severe pulmonary hypertension, and Eisenmenger syndrome with mild signs and symptoms of congestive heart failure that first appeared at the age of 39 years old. On physical examination, our patient had no cardiac murmur but a fixed split second heart sound at pulmonary area.

The electrocardiographic and radiological findings are non-specific [12], encountered in any condition causing left ventricular volume overload and PAH. Therefore, APW should be considered with other shunt lesions such as large ventricular septal defects (VSDs) or PDA, and should be looked for on echocardiography.

Echocardiography is usually able to demonstrate the lesion, its localization and its size [5, 13], although it can be difficult in cases of distal APWs. The diagnostic accuracy depends on the operator's expertise, the level of clinical suspicion, and the presence of associated lesions which reduces the technique's sensitivity $[14,15]$.

The diagnosis by 2DE should be made by visualizing the aortopulmonary septum in two or more different planes. The cross-sectional parasternal planes over the aortic valve plane, coronal subcostal plane of both outflow tracts, suprasternal longitudinal and upper parasternal planes are used. The defect between the aorta and the pulmonary artery can be best visualized and sized in the high parasternal short-axis view.

Some false positives are found because of the drop outs (artificial echo-loss phenomenon) that can occur in the region of the aortopulmonary septum in parasternal long and short axis views [10, 14].
To differentiate this phenomenon from true APW, the echocardiographer should resort to the T sign, aside from exploring the septum in several planes. This sign is reflected by the greater refringence (thickening) that the borders of the true defect acquire which is perpendicular to the rest of the septum and adopts a $\mathrm{T}$ image [15].

The Doppler color study is of inestimable aid. When the defect is large, it reveals a bidirectional shunt and reverse flow in the pulmonary artery, distal to the defect. Continuous high-speed flow by Doppler is seen only in small APW $(3-4 \mathrm{~mm})$, when there is no significant elevation of the pulmonary artery pressure $[15,16]$

Similar to large PDAs with PAH, flow across the shunt may not be easily visible on color Doppler, making diagnosis difficult.

In a high parasternal plane the defect can be visualized. The detection of a diastolic reversal flow in the descending aorta and in the arch indicates there is left-to-right shunt in diastole through the APW [17].

Doppler and color flow mapping contribute greatly to the diagnosis of APW by 2DE increasing the sensitivity of the echocardiogram for diagnosing the APW [11]. Nevertheless, in reported studies, neither the $\mathrm{T}$ sign nor Doppler color images provide a definitive diagnosis. The diagnostic performance of echocardiography approximates 57\% (70\% in simple APW and $37 \%$ in complex APW) [10, 15]. False diagnoses, both positive and negative, are not infrequent.

The presence of an associated lesion such as PDA makes the diagnosis of APW more difficult. In 2DE, PDA is a well visualized structure and, usually, there is continuous flow by Doppler and on color flow mapping [18].

In our case, the echocardiography identified a $10 \mathrm{~mm}$ patent ductus arteriosus with a left-to-right shunt, with doubt as to the presence of a small type II APW.

In doubtful cases, additional imaging techniques such as transesophageal echocardiography and magnetic resonance angiography can be useful in diagnosis [4]. In our patient, this may have clinched the diagnosis before the catheterization procedure, but she could not tolerate both radiographic exams showing acute dyspnea at rest and wheezing, which prompted us to stop.

The necessity of performing cardiac catheterization is important in difficult, doubtful and late presenting cases with suspected pulmonary hypertension $[1,13,19]$. 
Results of cardiac catheterization show the presence and size of the shunt; retrograde aortogram confirms the location and type of AP window. In Type I, The aorta and main pulmonary artery are visualized; in Type II, The aorta and left and right pulmonary arteries are seen, but not the main pulmonary artery. It also provides useful information concerning complex associated lesions, as well as revealing elevated pulmonary vascular resistance and whether it is reversible.

In our case, the angiographic and hemodynamic study confirmed the presence of a type II APW, with a left-to right shunt and severe isosystemic pulmonary hypertension. Pulmonary arteriolar resistance evaluation and cardiac output calculation with indirect Fick method were difficult to interpret.

Early recognition and surgical repair of APW as well as large PDA are imperative to avoid irreversible pulmonary vascular disease[20]. However, surgery is contraindicated in patients with Eisenmenger syndrome[11]. In our patient, the atypical clinical presentation and the radiographic and echocardiographic findings gave us the impression that she was still available for surgery. The cardiac catheterization infirmed our impression.

The current treatment strategy for PAH patients includes general measures (physical activity and supervised rehabilitation, infection prevention, psychosocial support), conventional treatments (oral anticoagulants, diuretics, O2, digoxin), and diseasespecific therapy with high-dose Calcium Channel Blockers (CCB) in vasoreactive patients or drugs approved for PAH in non-vasoreactive patients according to the prognostic risk of the patient[21].

Because of the symptomatic severe pulmonary hypertension, our patient received high dose aspirin and oxygenotherapy. She lacked financial means to afford specific vasodilatators.

Response to therapy is commonly evaluated with a variety of methods, including assessment of functional class, exercise tolerance, echocardiography, and right heart catheterization.

Uncorrected APW is associated with high mortality rates [22]. Very few cases of more than 40 years old with uncorrected APW were reported in the literature [23,24]. Furthermore, APW increases fetal and maternal mortality[24]. Our patient gave birth to a healthy child in her twenties without any respiratory and cardiac symptoms or complications, she had the first symptom at the age of 39 years old, and until this date she survives despite the relatively altered quality of life. This very unusual and inexplicable natural history seems to merit to be reported.

\section{CONCLUSION}

Aortopulmonary window may rarely present in adulthood. However, It should be considered whenever the course of complex congenital heart disease includes cardiac failure and pulmonary hypertension. The diagnosis can usually be made by careful echocardiography which is quite sensitive in detecting APWs in adults even with severe PAH, although occasionally it does result in some false positive and negative diagnoses. For this reason, APWs may only be confirmed on cardiac catheterization. In half of all cases it is associated with other congenital heart anomalies, which should be looked for. Early surgical closure of the APW is now the first-line therapeutic option and should include repair of any associated lesions in order to prevent the development of irreversible pulmonary vascular disease.

\section{REFERENCES}

1. Jacobs JP, Quintessenza JA, Gaynor JW, Burke RP, Mavroudis C. Congenital Heart Surgery Nomenclature and Database Project: aortopulmonary window. Ann Thorac Surg. 2000;69(4 Suppl):S44-49.

2. Mori K, Ando M, Takao A, Ishikawa S, Imai Y. Distal type of aortopulmonary window. Br Heart J. 1978; 40:681-9.

3. Erez E, Dagan O, Georghiou G, Gelber O, Vidne B, Birk E. Surgical management of aortopulmonary window and associated lesions. Ann Thorac Surg. 2004; 77: 484-7.

4. Gangana C, Malheiros A, Alves E, Azevedo M, Bernardes R, Simões L. Janela Aortopulmonar Impacto das lesões associadas no resultado cirúrgico. Arq Bras Cardiol. 2007; 88(4): 402-407.

5. Aggarwal SK, Mishra J, Sai V, Iyer VR, Panicker BK. Aortopulmonary window in adults: diagnosis and treatment of late-presenting patients. Congenit Heart Dis. 2008; 3:341-346.

6. Backer CL, Mavroudis C. Surgical management of aortopulmonary window: a 40-year experience. Eur J Cardiothorac Surg. 2002; 21:773-779.

7. Perloff JK. Clinical Recognition of Congenital Heart Disease, 5th edn. Philadelphia, Pa: Saunders; 2003.

8. Bagtharia R, Trivedi K, Burkhart H. Outcomes for patients with an aortopulmonary window, and the impact of associated cardiovascular lesions. Cardiol Young. 2004; 14: 473-80.

9. Comin J, Manito N, Roca J, Castells E, Esplugas E. Insuficiencia mitral funcional. Fisiopatología e impacto del tratamiento médico y de las técnicas quirúrgicas de reducción ventricular izquierda. Rev Esp Cardiol. 1999;52:512-20.

10. Moruno Tirado A, Santos de Soto J, Grueso Montero J, Gavilán Camacho JL, Álvarez Madrid A, Gil Fournier M, Descalzo Señorans A. Aortopulmonary window: clinical assessment and 
surgical results. Revista Española de Cardiología (English Edition). 2002 Mar 1;55(3):266-70.

11. A Soares AM, Atik E, Cortez TM. Aortopulmonary window. Clinical and surgical assessment of 18 cases. Arq Bras Cardiol. 1999;73:59-74.

12. Insuficiência mitral por dilatação secundária do anel valvar. Arq Bras Cardiol. 1994; 63: 493-5.

13. Kervancioglu S, Soydinc S, Davutoglu V, Kervancioglu R, Sirikci A, Bayram M. Aortopulmonary window: a rare adult case demonstration by echocardiography, MRI, CEMRA and angiography. Cardiovasc Intervent Radiol. 2004;27:175-178.

14. Snider RA, Serwer AG, Ritter BS. Echocardiography in Pediatric Heart Disease, $2^{\mathrm{a}}$ ed. Mosby. 1997; 292-293.

15. Balaji S, Burch M, Sullivan I. Accuracy of crosssectional echocardiography in diagnosis of aortopulmonary window. Am J Cardiol. 1991; 67: 650-3.

16. Rice MJ, Seward JD, Hagler DJ, Mair DD, Tajik AJ. Visualization of aortopulmonary window by two dimensional echocardiography. Mayo Clin Proc. 1982; 57: 482-7.

17. Horimi H, Hasegawa T, Shiraishi H, Endo H, Yanagisawa $M$. Detection of aortopulmonary window with ventricular septal defect by Doppler color flow imaging. Chest. 1992; 101: 280-1.

18. Moss AJ, Adams FH. Heart disease in infants, children, and adolescents. Including The Fetus and Young Adult. $5^{\mathrm{a}}$ edition. Williams and Wilkins. 1995: 764-8.

19. Bhan A, Gupta M, Abraham S, Sharma R, Kothari S, Juneja R. Surgical experience of aortopulmonary window repair in infants. Interact CardioVasc and Thorac Surg. 2007; 6: 200-203.

20. Van Son JA, Puga FJ, Dandzlson GK, Seward JB, Mair DD, Schaff HV, Ilstrup DM. Aortopulmonary window: factors associated with early and late success after surgical treatment. InMayo Clinic Proceedings. Elsevier. 68(2):128-133

21. Galiè N, Humbert M, Vachiery JL, Gibbs S, Lang I, Torbicki A, Simonneau G, Peacock A, Vonk Noordegraaf A, Beghetti M, Ghofrani A, Gomez Sanchez MA, Hansmann G, Klepetko W, Lancellotti P, Matucci M, McDonagh T, Pierard LA, Trindade PT, Zompatori M, Hoeper M, Aboyans V, Vaz Carneiro A, Achenbach S, Agewall S, Allanore Y, Asteggiano R, Paolo Badano L, Albert Barberà J, Bouvaist H, Bueno H, Byrne RA, Carerj S, Castro G, Erol Ç, Falk V, Funck-Brentano C, Gorenflo M, Granton J, Iung B, Kiely DG, Kirchhof P, Kjellstrom B, Landmesser U, Lekakis J, Lionis C, Lip GY, Orfanos SE, Park MH, Piepoli MF, Ponikowski P, Revel MP, Rigau D, Rosenkranz S, Völler H, Luis Zamorano J. 2015 ESC/ERS Guidelines for the diagnosis and treatment of pulmonary hypertension. Eur Heart J. 2016 Jan 1;37(1):67-119.

22. Backer CL. "Aortopulmonary window and aortic origin of a pulmonary artery," in Pediatric Cardiac Surgery. 2003.

23. Niles NR and Schmidt WA. "Aortopulmonary septal defect and longevity," Chest. 1980;78(2): 336-338.

24. Su- Mei AK, Ju- Le T. Large unrepaired aortopulmonary window-survival into the seventh decade. Echocardiography. 2007 Jan;24(1):71-3. 